\title{
Feasibility Analysis of Autogenous Tooth-based Bone Graft Material after Guided Bone Regeneration Technique
}

Chang Hee-Yung ${ }^{1}$, Kwon Taek-Ka ${ }^{2}$, Nunn $\mathrm{ME}^{3}$, Miyamoto $\mathrm{T}^{3}$, Lee Kwang-Won ${ }^{4}$, Kim Young-Kyun ${ }^{5}$ and Lee Hyo-Jung ${ }^{*}$

${ }^{1}$ Department of Periodontology, School of Dentistry, Wonkwang University, Iksan, Jeonbuk, Korea

${ }^{2}$ Department of Prosthodontics, St. Vincent's Hospital, Catholic University, Gyeonggi-do, Korea

${ }^{3}$ Department of Periodontics, School of Dentistry, Creighton University, NE, USA

${ }^{4}$ Department of Periodontology, Section of Dentistry, Seoul National University Bundang Hospital, Gyeonggi-do,

Korea

${ }^{5}$ Department of Oral and Maxillofacial Surgery, Seoul National University Bundang Hospital, Gyeonggi-do, Korea

${ }^{*}$ Corresponding author: Lee Hyo-Jung, DDS, Ph.D., Department of Periodontology, Section of Dentistry, Seoul National University Bundang Hospital, 82 Gumi-ro, 173 Beon-gil, Bundang-gu, Seongnam-si, Gyeonggi-do, 463-707, Republic of Korea, Tel: 82-31-787-2780, Fax: 82-31-787-4068, E-mail: periolee@ gmail.com

Citation: Chang Hee-Yung, Kwon Taek-Ka, Nunn ME, Miyamoto T, Lee Kwang-Won, et al. (2014) Feasibility Analysis of Autogenous Tooth-based Bone Graft Material after Guided Bone Regeneration Technique. J Case Rep Stud 2(3): 304. doi: 10.15744/2348-9820.1.604

Received Date: May 20, 2014 Accepted Date: June 20, 2014 Published Date: June 20, 2014

\begin{abstract}
Background: We set out to determine the possibility of radiographically evaluating the degree of marginal bone loss in humans after functional loading of implants at sites of guided bone regeneration (GBR) with autogenous tooth-based bone graft (ATBBG) material (AutoBT, Korea Tooth Bank, Seoul, Korea).

Materials and Methods: Using ATBBG material, GBR procedures were performed on the extraction sockets with bone defects such as buccal dehiscence and 6 months of healing was allowed. Dental implants were installed and prosthetic procedures were done after another 6 months of healing. Marginal bone levels (MBLs) were radiographically measured following functional loading (mean duration, 10 months; range, 4-18 months) in 10 patients among 19 patients initially enrolled in this study (4 men and 6 women; age range, 39-65 years; mean age, 55.4 years) who maintained follow-up visits after entire surgical and prosthetic procedures.

Results: No significant MBL differences were noted immediately after GBR, implant placement and prosthesis delivery ( $\mathrm{F}=0.245$, $\mathrm{P}>0.05)$. Changes in the MBLs were not affected by gender.

Conclusion: The ATBBG material is viable for GBR and can yield a stable MBL even after functional loading of implants. The degree of marginal bone loss after loading with ATBBG is stable.
\end{abstract}

Keywords: Bone regeneration; Dental implants; Radiography; Retrospective studies; Tooth

\section{Introduction}

In the field of dentistry, many and increasingly diversified biomaterials are used to overcome functional and esthetic problems via restoration of defects in hard and soft tissues [1]. An autograft showing osteogenesis, osteogenic induction, and conduction capacity would clearly be the ideal biomaterial for restoration of hard tissue defects. However, such autografts also have disadvantages such as secondary defects at the donor site, limited availability in terms of size, and seemingly inevitable resorption after implantation. Therefore, several other options such as allografts, xenografts, and alloplastic bones have been developed.

Our Department of Dentistry Hospital has been conducting experimental research to develop a biomaterial using both animal and human teeth [2-11]. Previous study indicated that bone graft substitution involving the particulate dentin of animals and humans can be used in restoring hard tissue defects in the oral and maxillofacial areas $[6,11,12]$.

On the basis of the aforementioned research on tooth development and the fact that the tooth components are very similar to those of alveolar bone, we have developed AutoBT ${ }^{\circledast}$ particles (AutoBT ${ }^{\oplus}$, Korea Tooth Bank, Korea) as a new bone graft material created from extracted autogenous teeth $[12,13]$. In other words, autogenous tooth-based bone graft (ATBBG) material is fabricated as particles and then is autografted [12,13]. The ATBBG material includes both mineral and organic elements and it is used on an individual basis only for those patients who provide an extracted tooth. Moreover, ATBBG material showed structures and physicochemical characteristics similar to those of autogenous cortical bones [14]. ATBBG material consists of inorganic components such as calcium phosphate (low-crystalline hydroxyapatite (HA), tricalcium phosphate (TCP), octacalcium phosphate 
(OCP), and amorphous calcium phosphate (ACP) [12]. Scanning electron microscopic (SEM) examination revealed HA crystalline structure and collagen fibers around the dentinal tubules [12,13]. Previous research on organic elements removed from allogeneic or animal teeth to eliminate the risk of infection transmission suggested that alveolar bone remodeling can only proceed promptly-and that better prognosis can be expected-when organic elements are preserved [12]. The authors reported that inorganic and organic components, such as noncollagenous proteins which were included in ATBBG material showed potential osteoconductivity and osteoinductivity. We applied these findings to the clinical and histomorphometric analytical investigation of collected specimens, demonstrating that new bone was generated as the bone graft material was absorbed over time and also indicating that the mechanism underlying this effect appeared to reflect both bone induction and bone conduction [12].

Due to the paucity of studies on the ATBBG material we sought to gain insight into the degree of marginal bone loss after ATBBG grafting by analyzing radiographic films taken after guided bone regeneration (GBR) procedures, implant placement, prosthesis delivery and throughout follow-up.

\section{Materials and Methods}

\section{Patient enrollment}

This study was approved by Institutional Review Board (IRB) of Seoul National University Bundang Hospital (No: B-1104-126104). Among the patients who underwent GBR using the ATBBG material between December 2008 and December 2010 at Seoul National University Bundang Hospital, 19 patients (8 men and 11 women; aged 39-70, mean age 53.7) were enrolled for GBR with ATBBG. No patient had serious systemic disease or major conditions that would affect comorbidity such as uncontrolled diabetes, psychiatric problems, malignant neoplasm or pregnancy. Among these 19 patients, only 12 patients (5 men and 7 women; aged 39-65, mean age 53.2) who revisited the hospital after the prosthesis delivery were enrolled at our institution for the analysis of marginal bone change. Seven patients did not finish prosthesis delivery or went to private clinics to continue prosthesis delivery mostly due to financial or convenience issues. The level of marginal bone loss (MBL) after restoration was only measured in 10 of these 12 patients ( 4 men and 6 women), for whom barrier membranes for bone graft materials were used at the time of GBR. GBR was performed using ATBBG material in the maxilla and the mandible in 3 and 7 patients respectively. A detailed description is shown in Table 1.

\begin{tabular}{|c|c|c|c|c|c|c|c|}
\hline $\begin{array}{c}\text { Patient } \\
\text { identifica- } \\
\text { tion code }\end{array}$ & Sex & Age & Area & $\begin{array}{c}\text { GBR } \\
(\mathbf{m m})\end{array}$ & $\begin{array}{c}\text { Implant } \\
\text { placement } \\
(\mathbf{m m})\end{array}$ & $\begin{array}{c}\text { Prosthesis } \\
\text { delivery } \\
(\mathbf{m m})\end{array}$ & $\begin{array}{c}\text { Follow-up } \\
(\mathbf{m m})\end{array}$ \\
\hline 1 & $\mathrm{~m}$ & 55 & $\# 15$ & 6.89 & 6.61 & 4.84 & 4.5 \\
\hline 2 & $\mathrm{~m}$ & 39 & $\# 47$ & 3.43 & 4.46 & 4.1 & 4.41 \\
\hline 3 & $\mathrm{f}$ & 55 & $\# 36$ & 3.58 & 6.11 & 5.16 & 5.32 \\
\hline 4 & $\mathrm{f}$ & 43 & $\# 46$ & 6.52 & 7.31 & 6.98 & 6.08 \\
\hline 5 & $\mathrm{f}$ & 57 & $\# 21, \# 23$ & 5.01 & 5.25 & 5.89 & 7.14 \\
\hline 6 & $\mathrm{~m}$ & 58 & $\# 47$ & 9.87 & 10.77 & 8.27 & 9.44 \\
\hline 7 & $\mathrm{f}$ & 56 & $\# 37$ & 3.06 & 3.51 & 3.31 & 3.33 \\
\hline 8 & $\mathrm{~m}$ & 56 & $\# 47$ & 8.41 & 10.33 & 8.43 & 7.7 \\
\hline 9 & $\mathrm{f}$ & 65 & $\# 16$ & 5.85 & 7.48 & 8.55 & 7.61 \\
\hline 10 & $\mathrm{f}$ & 64 & $\# 46$ & 4.17 & 4.77 & 4.43 & 4.44 \\
\hline
\end{tabular}

Follow-up: date of last hospital visit after prosthesis delivery

Tooth was coded as FDI Two-Digit Notation

Recorded as mm indicating the distance between the cement-enamel junction of the adjacent natural tooth and marginal bone

Table 1: Patient information

\section{ATBBG material processing methods}

Storage of extracted tooth and requests for ATBBG material processing: Fully informed consent concerning the processing method for ATBBG and its use was obtained from each patient. Upon patient consent, a processing request is prepared, which required the patient to sign a document indicating that his or her own tooth would be processed.

Processing and implantation of ATBBG: The extracted tooth was stored refrigerated in saline according to the manufacturer's instructions and transferred for ATBBG mateiral processing. According to the description in previous studies, the Korea Tooth Bank produced ATBBG, sterilized, packed, and transported it to the hospital according to their protocol (Figure1) [12,13]. Individual ATBBG material was prepared only for individual patients who had provided the extracted tooth. 


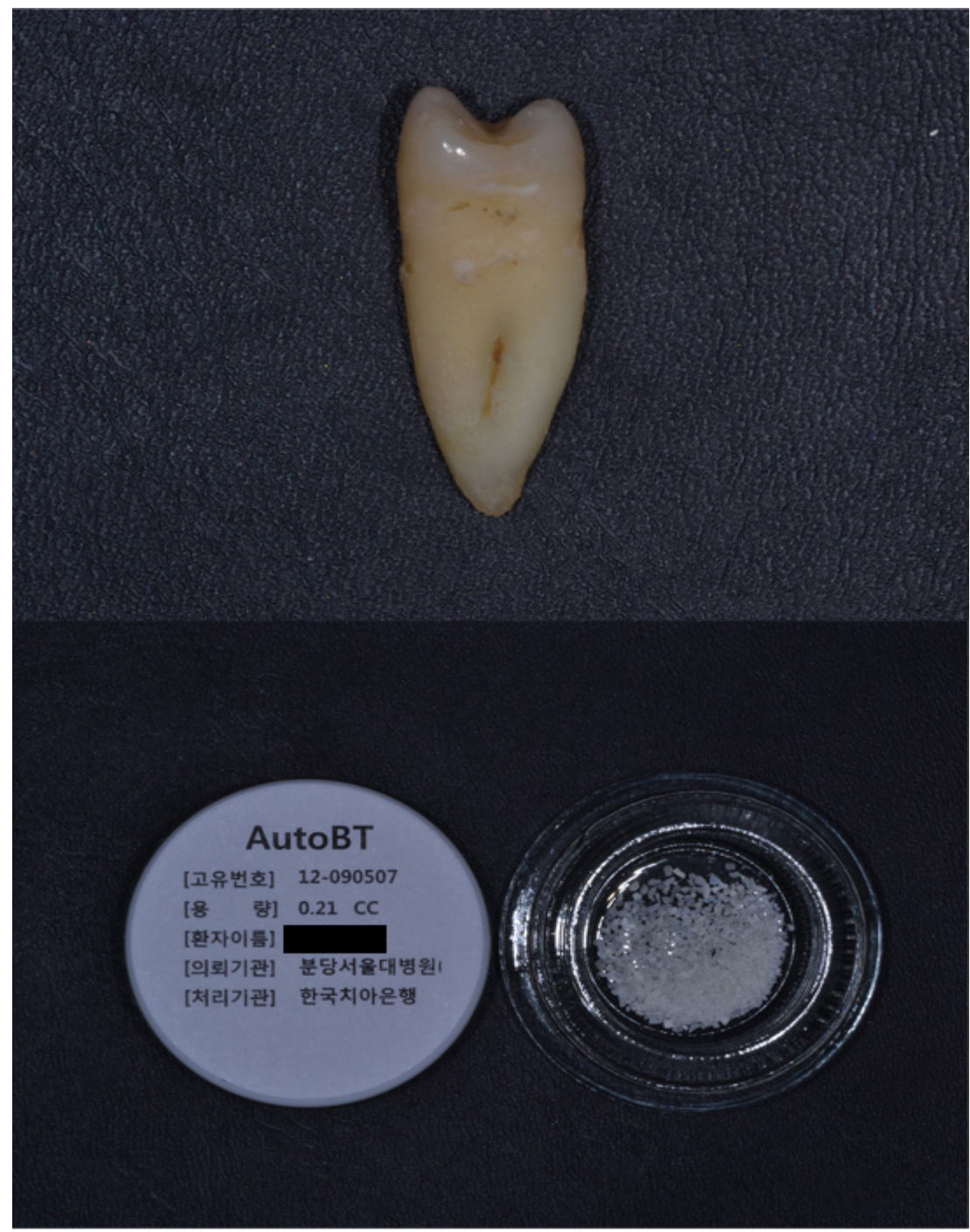

Figure 1: An extracted tooth and ATBBG material.

(Upper) extracted tooth was sent for created of ATBBG material

(Lower) ATBBG was delivered in a container on which was written the date of the order, the pateint name, total amount (cc), the orderer, and manufacturer ( AutoBT" ).

\section{Surgical and prosthetic procedures}

All surgical procedures including GBR and implant placements were performed by one periodontist (Chang HY). After tooth extraction, extracted tooth was transferred for preparation of ATBBG material and soft tissue healing was allowed for 2 weeks. And then, a full-thickness flap was reflected and GBR procedures were performed on the extracted socket (Figure 2). The sites of GBR procedures were bone defects such as infra-bony defects including buccal dehiscence bone defects. ATBBG material was placed on the bone defects and barrier membrane was covered to cover bone graft materials. Resorbable barrier membrane (BioGide, Geistlich Pharma AG, Wolhusen, Switzerland) was used in 8 patients and non-resorbable membrane (Gore-tex, W.L. Gore \& Associates, Flagstaff, AZ, USA) was used in one patient, and both resorbable and non-resorbable membranes were used in one patient. Then primary flap closure was done. After 6 months of healing, barrier membranes were removed and dental implants were installed in healed sites according to the manufacturer's instruction under saline irrigation and submerged. We used a single type of implant (Superline, Dentium Co., Ltd, Seoul, Korea) for all patients. After healing periods of 6 months, implant uncovering surgery for further prosthetic procedures was performed. After soft tissue healing, prosthetic procedures were done. All prosthesis deliveries were performed by one prosthodontist. After prosthetic procedures were completed, patients were revisited for regular check-up.

\section{Radiographic data filing}

Panoramic and periapical radiographs were taken at each stage of treatment; after GBR for the extraction socket using ATBBG, after implant placement, after prosthesis delivery, and after functional loading for 4 18 months (mean duration: 10 months), using an Orthopantomograph OP 100 (Instrumentarium Dental, Nahkelantie 160, Tuusula, Finland/HELIODENT DS; Sirona Dental Systems, GmbH, Bensheim, Germany). 


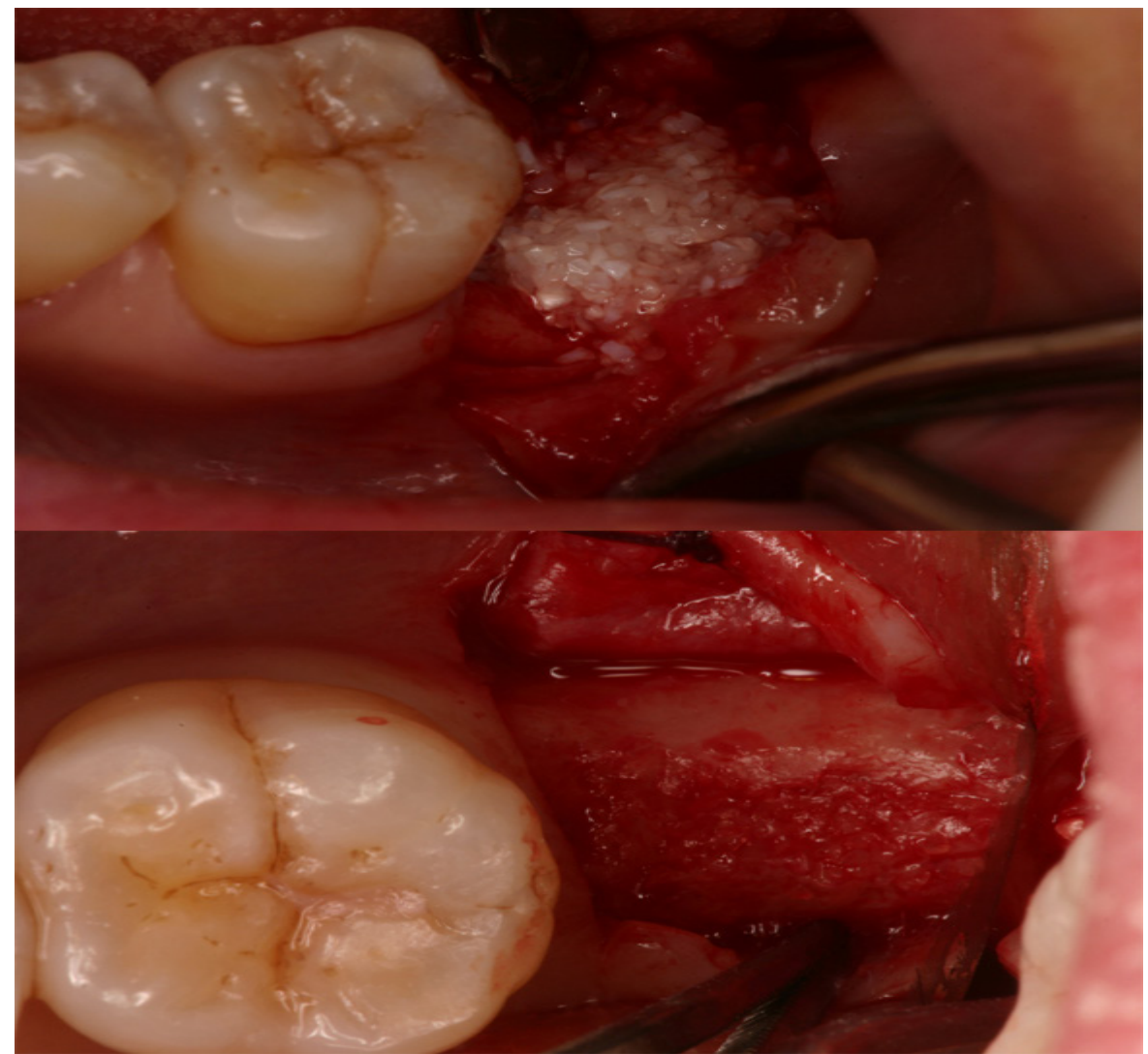

Figure 2: Clinical figures of GBR procedure.

\#37area received GBR procedure and re-opening for implant.

(Upper) A 56-year-old woman underwent GBR using ATBBG material.

(Lower) she revisited for the implant procedure. The grafted area was filled with newbone and residual of graft materials.

\section{Measurement of the marginal bone level}

Panoramic and periapical radiographic images were saved in DICOM format (Digital Imaging and Communications in Medicine, PACS view), and the one researcher who was not involved in surgical and prosthetic procedures measured the height up to the position of the marginal bone in the region where GBR was performed with the measurement tool in the software (Infinite Pacs, Infinitt Healthcare Co., Ltd; Korea), using the cement-enamel junction (CEJ) of the adjacent tooth as the base point repeatedly (Figure 3).

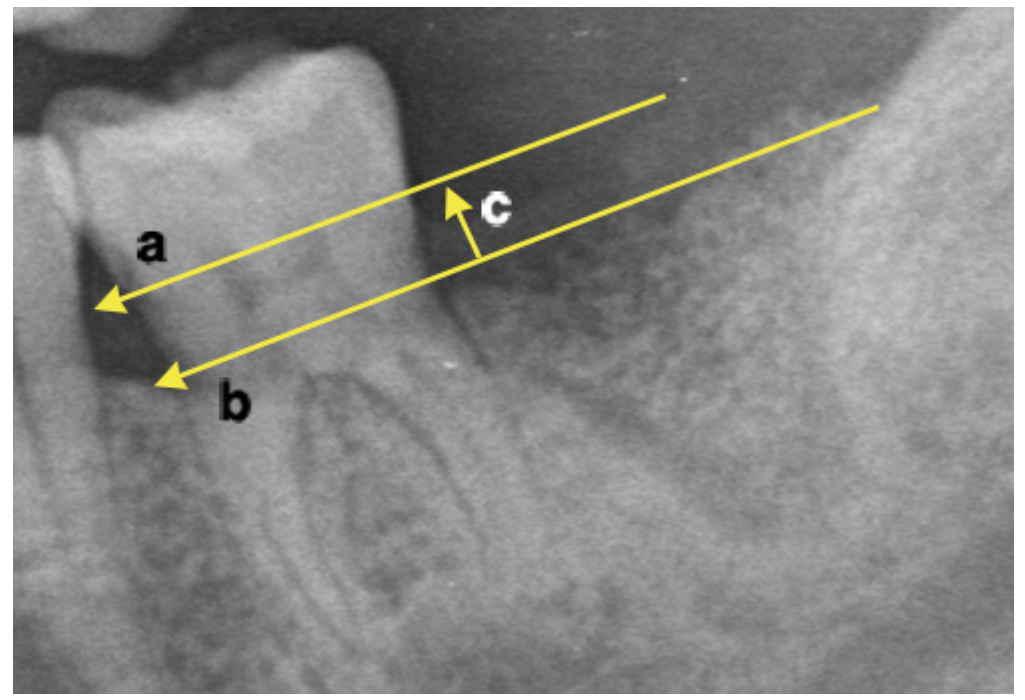

Figure 3: Periapical radiographs.

a: Location of the CEJ of the adjacent natural teeth

b: Location of the marginal bone after GBR

c: Distance between a and b 


\section{Statistical analysis}

Data were statistically processed using SPSS software (PASW Statistics 18.0, SPSS Inc., Chicago, IL, USA). Differences in the height of marginal bone among the radiographic films taken after GBR, implant placement, prosthesis delivery and on the last follow-up were compared with Student's paired $t$-test. Correlation between the variations of marginal bone height according to gender was assessed by independent sample $t$-test.

\section{Results}

In each patient, the mean height of the marginal bone in the GBR region was measured after GBR, implant placement, prosthesis delivery and at the time of the last hospital visit was confirmed to vary relative to the CEJ of the adjacent tooth (Table 2, $\mathrm{P}$ $<0.01)$. No significant differences in the MBLs were noted immediately after GBR, implant placement and prosthesis delivery $(\mathrm{F}=0.245, \mathrm{P}>0.05)$. A statistically significant correlation was observed between the height of the marginal bone after $\mathrm{GBR}$ and that after implant placement (Table 2; correlation coefficient $=0.937, \mathrm{P}<0.01$ ), indicating that the height after GBR did not change substantially even after implant placement (Table 3; mean $=-0.981$; standard deviation=0.8376; $\mathrm{P}<0.01$ ).

Male and female patients demonstrated a statistically significant difference in the position of the marginal bone after prosthesis delivery compared with that after GBR and implant placement (Table 3; after GBR, male mean value $=-0.74$, female mean value $=1.0217, \mathrm{P}<0.05$; after implant placement, male mean value $=-1.6325$, female mean value $=-0.0183, \mathrm{P}<0.05$ ). There was no complication during the total observation period.

\begin{tabular}{|c|c|c|c|c|c|}
\hline & $\Delta$ Distance & $\begin{array}{c}\text { Mean } \\
(\mathbf{m m})\end{array}$ & $\begin{array}{c}\text { Standard } \\
\text { deviation }\end{array}$ & $\begin{array}{c}\text { Correlation } \\
\text { coefficient }\end{array}$ \\
\hline a & SURGICAL HEALING PERIOD (i-ii) & -0.98 & 0.8376 & $-3.704^{* *}$ & 0.937 \\
\hline b & START OF LOADING (i-iii) & -0.31 & 1.37878 & -0.727 & 0.796 \\
\hline c & TOTAL FOLLOW-UP (i-iv) & -0.29 & 1.37679 & -0.668 & 0.797 \\
\hline d & IMPLANT HEALING PERIOD (ii-iii) & 0.66 & 1.12719 & 1.863 & 0.887 \\
\hline e & IMPLANT FOLLOW UP (ii-iv) & 0.69 & 1.26256 & 1.728 & 0.852 \\
\hline f & PROSTHESIS FOLLOW-UP (iii-iv) & 0.02 & 0.76699 & 0.107 & 0.922 \\
\hline
\end{tabular}

$\triangle$-Distance: differences in the distances from CEJ of the adjacent tooth to the marginal bone between each phase

i-after GBR: baseline

ii-after implant placement

iii-after prosthesis delivery

iv-last follow-up

Table 2: Mean differences and correlation coefficient between each phase $(n=10, P<0.01)$

\begin{tabular}{|c|c|c|c|c|c|}
\hline & $\Delta$ Distance & & $\begin{array}{l}\text { Male } \\
(\mathrm{mm})\end{array}$ & $\begin{array}{c}\text { Female } \\
(\mathrm{mm})\end{array}$ & $\mathbf{t}$ \\
\hline \multirow{2}{*}{$\mathrm{a}$} & \multirow{2}{*}{ SURGICAL HEALING PERIOD (i-ii) } & Mean & 0.89 & 1.04 & \multirow{2}{*}{0.258} \\
\hline & & Standard deviation & 0.8732 & 0.9036 & \\
\hline \multirow{2}{*}{$\mathrm{b}$} & \multirow{2}{*}{ START OF LOADING (i-iii) } & Mean & -0.74 & 1.02 & \multirow{2}{*}{$2.483^{*}$} \\
\hline & & Standard deviation & 1.29375 & 0.96329 & \\
\hline \multirow{2}{*}{ c } & \multirow{2}{*}{ TOTAL FOLLOW-UP (i-iv) } & Mean & -0.7 & 0.95 & \multirow{2}{*}{2.25} \\
\hline & & Standard deviation & 1.28025 & 1.0516 & \\
\hline \multirow{2}{*}{ d } & \multirow{2}{*}{ IMPLANT HEALING PERIOD (ii-iii) } & Mean & -1.63 & -0.01 & \multirow{2}{*}{$3.107^{*}$} \\
\hline & & Standard deviation & 0.90596 & 0.73749 & \\
\hline \multirow{2}{*}{ e } & \multirow{2}{*}{ IMPLANT FOLLOW UP (ii-iv) } & Mean & -1.59 & -0.08 & \multirow{2}{*}{2.227} \\
\hline & & Standard deviation & 1.00536 & 1.07925 & \\
\hline \multirow{2}{*}{$\mathrm{f}$} & \multirow{2}{*}{ PROSTHESIS FOLLOW-UP (iii-iv) } & Mean & 0.03 & -0.06 & \multirow{2}{*}{-0.194} \\
\hline & & Standard deviation & 0.81937 & 0.80691 & \\
\hline
\end{tabular}

$\Delta$-Distance: differences in the distances from CEJ of the adjacent tooth to the marginal bone between each phase

i-after GBR: baseline

ii-after implant placement

iii-after prosthesis delivery

iv-last follow-up

Table 3: Relationship between sex and differences between each phase $(n=10$, male $=4$, female $=6, P<0.05)$ 


\section{Discussion}

We set out to gain insight into the degree of MBL after ATBBG grafting by analyzing radiographic films taken after GBR, implant placement, prosthesis delivery and during follow-up. This study showed a statistically significantly high correlation between the height of the marginal bone after GBR and after implant placement, and indicates that the height of marginal bone after GBR remains unchanged even through the last follow-up appointment, without any complication. Due to the inherent weakness of the retrospective study design, we could analyze only the data of patients who completed their follow-up despite the financial burden. Furthermore, because the ATBBG material was a new product, very few patients were familiar with it and they were therefore hesitant to participate in the study. In addition, the included cases were limited only to those patients who underwent surgery using both ATBBG and membrane. These were the main reasons why the number of subjects in the series was small.

In our study, membrane was not uniformly used because the periodontist chose the type of membrane according to the character of the alveolar bone defect for the benefit of the patient. Consequently there was naturally some inconsistency in the types of membrane because we enrolled cases consecutively. Regarding whether the type of membrane affects the extent of marginal bone loss, a recent study on membrane use with AutoBT ${ }^{\circledast}$ concluded that the application of a resorbable membrane was not a critical factor in GBR when using AutoBT ${ }^{\oplus}[15]$. Furthermore, Rasmusson et al. suggested that there was no difference in implant stability and bone regeneration between the groups with or without membrane following implant placement [16].

Additionally, Kim et al. conducted a study in which AutoBT ${ }^{\circledast}$ was compared with a variety of other bone grafting materials via SEM, x-ray diffraction and the Ca/P dissolution test [14]. The compared bone graft materials were xenograft (Bio-Oss, Geistlich Pharma AG), alloplastic materials (MBCP, Biomatlante, Vigneux de Bretagne, France), allografts (ICB, Rocky Mountain Tissue Bank, Aurora, CO, USA) and autogenous mandibular cortical bone. They concluded that AutoBT ${ }^{\oplus}$ was most similar to autogenous cortical bone due to the nature of the biodegradable biomaterial, possessing a compact microporous and low crystalline structure. Taken together, with their somewhat limited findings, membrane application may not critically affect GBR outcomes because the defect shape or the qualities of graft materials themselves are more crucial factors than the characteristics of the membrane itself [18-20].

Although a single investigator measured all bone levels, errors may occur when the marginal bone around the implant is evaluated at positions where osseointegration occurred. Because the width of the alveolar bone and position of the fixture differ along the direction of the bucco-lingual side, the fixture axle and film plane are not completely parallel [21]. Many research studies performed in the past used clinical measurement of the probing depth as an index to indicate the condition of tissue around the implant [22-24]. However, the probing depth cannot be completely measured because the exposed fixture thread of the Brånemark fixture interrupts probing. Therefore, it would appear that the level of marginal bone around the implant can be more accurately measured radiographically than by the clinical measurement of the probing depth [25]. Moreover taking x-ray images was not standardized, and the mixed usage of panorama and periapical images might actually result in measurement errors. However, we analyzed with high-technology software, including Infinite Pacs, which can calculate distance, thus implant fixture could be used as an assistant reference after implant placement.

This investigation has some limitations. First of all, it was a retrospective study with a high dropout rate, perhaps because of the financial burden on individual patients. Therefore, there might be some selection bias. Moreover, the periods during which functional loading was applied after prosthesis delivery and follow-up were relatively short, and some clinical factors differed among individual patients, especially concerning systemic conditions, reasons for extraction, and the intervals between GBR, implant placement, and prosthesis delivery. However, there are almost no publications on the use of AutoBT ${ }^{\varpi}$ as ATBBG material in the international literature. Therefore, the present data appear important in evaluating the clinical results of this new method of GBR using ATBBG material. In future, meticulously planned prospective studies, perhaps with some financial health care subsidies, are needed to thoroughly evaluate ATBBG performance.

\section{Conclusions}

In conclusion, the amount of MBL in the region of GBR and implant placement using ATBBG remains stable, and findings are similar to those in the area using traditional bone graft materials. Therefore, we can justifiably conclude that ATBBG material warrants further wide-scale evaluation as a bone graft material for GBR.

\section{Acknowledgments}

No authors have any conflicts of interest relevant to this article. Hee-Yung Chang and Taek-Ka Kwon contributed equally to this work. We appreciate to Jung-tae Lee for his technical assistance. The authors are also indebted to J. Patrick Barron, Professor Emeritus, Tokyo Medical University and Adjunct Professor, Seoul National University Bundang Hospital for his pro bono editing of this manuscript.

\section{References}

1. Kim SG, Yeo HH, Kim YK (1999) Grafting of large defects of the jaws with a particulate dentin-plaster of Paris combination. Oral Surg Oral Med Oral Pathol Oral Radiol Endod 88: 22-5.

2. Kim SG, Kim HK, Lim SC (2001) Combined implantation of particulate dentin, plaster of Paris, and a bone xenograft (Bio-Oss) for bone regeneration in rats. J Craniomaxillofac Surg 29: 282-8. 
3. Kim SG, Chung CH, Kim YK, Park JC, Lim SC (2002) Use of particulate dentin-plaste of Paris combination with/without platelet-rich plasma in the treatment of bone defects around implants. Int J Oral Maxillofac Implants 17: 86-94.

4. Kim SY, Kim SG, Lim SC, Bae CS (2004) Effects on bone formation in ovariectomized rats after implantation if tooth ash and plaster of Paris mixture. J Oral Maxillofac Surg 62: 852-7.

5. Park SS, Kim SG, Lim SC, Ong JL (2008) Osteogenic activity of the mixture of chitosan and particulate dentin. J Biomed Mater Res 87A: 618-23.

6. Ku HR, Jang HS, Kim SG, Jeong MJ, Park JC, et al. (2007) Guided tissue regeneration of the mixture of human tooth ash and plaster of Paris in dogs. Key Eng Mater 330-332: 1327-30.

7. Na TH, Kim SG, Yoon JH, Lim SC (2004) Effect of the bone regeneration of the mixture of human or bovine tooth ash and the plaster of Paris in rats. J Korean Assoc Maxillofac Plast Reconstr Surg 26: 334-40.

8. Kim YK, Yeo HH, Ryu CH, Lee HB, Byun UR, et al. (1993) An experimental study on the tissue reaction of tooth ash implanted in mandible body of the mature dog. J Korean Maxillofac Plast Reconstr Surg 15: 129-36.

9. Kim YK, Yeo HH, Cho JO. (1996) The experimental study of implantation combined with plaster of Paris in the rats: comparison according to the mature dog. J Korean Maxillofac Plast Reconstr Surg 18: 26-32.

10. Kim YK, Yeo HH, Yang IS, Seo JH, Cho JO (1994) Implantation of tooth ash combined with plaster of Paris: experimental study. J Korean Maxillofac Plast Reconstr Surg 16: 122- 9.

11. Kim YK, Ko YM (1997) Biomechanical study of the calvarial defects after implantation of the tooth ash and plaster in the rat. J Korean MaxillofacPlastReconstr Surg 19: 45-54.

12. Kim YK, Kim SG, Byeon JH, Lee HJ, Um IU, et al. (2010) Development of a novel bone grafting material using autogenous teeth. Oral Surg Oral Med Oral Pathol Oral Radiol Endod 109: 496-503.

13. Kim YK, Kim SG, Oh JS, Jin SC, Son JS, et al. (2011) Analysis of the inorganic component of autogenous tooth bone graft material. J Nanosci Nanotechnol 11: $7442-5$.

14. Kim YK, Kim SG, Yun PY, Yeo IS, Jin SC, et al. (2012) Autogenous teeth used for bone grafting: a comparison with traditional grafting materials. Oral Surg Oral Med Oral Pathol Oral Radiol 117: e39-45.

15. Lee JY, Lee J, Kim YK (2013) Comparative analysis of guided bone regeneration using autogenous tooth bone graft material with and without resorbable membrane. J Dent Sci 8: 281-6.

16. Rasmusson L, Meredith N, Kahnberg Ke, Sennerby L (1999) Effects of barrier membranes on bone resorption and implant stability in onlay bone grafts. An experimental study. Clin Oral Implants Res 10: 267-77.

17. Ellegaard B, Löe H (1971) New attachment of periodontal tissues after treatment of intrabony lesions. J Periodontol 42: 648-52.

18. Selvig KA, Kersten BG, Wikesjö UM (1993) Surgical treatment of intrabony periodontal defects using expanded polytetrafluoroethylene barrier membranes: influence of defect configuration on healing response. J Periodontol 64: 730-3.

19. Tonetti MS, Pini-Prato G, Cortellini P (1993) Periodontal regeneration of human intrabony defects. IV. Determinants of healing response. J Periodontol 64: 934-40.

20. Tonetti MS, Prato GP, Cortellini P (1996) Factors affecting the healing response of intrabony defects following guided tissue regeneration and access flap surgery. J Clin Periodontol 23: 548-56.

21. Sewerin IP (1990) Errors in radiographic assessment of marginal bone height around osseointegrated implants. Scand J Dent Res 98: 428-33.

22. Quirynen M, van Steenberghe D, Jacobs R, Schotte A, Darius P (1991) The reliability of pocket probing around screw-type implants. Clin Oral Implants Res 2: $186-92$.

23. Ericsson I, Lindhe J (1993) Probing depth at implants and teeth. An experimental study in the dog. J Clin Periodontol 20: 623-7.

24. Lang NP, Wetzel AC, Stich H, Caffesse RG (1994) Histologic probe penetration in healthy and inflamed perio-implant tissues. Clin Oral Implants Res 5: 191-201. 25. Isidor F (1997) Clinical probing and radiographic assessment in relation to the histologic bone level at oral implants in monkeys. Clin Oral Implants Res 8: $255-64$. 